\title{
Recent scientific research progress and challenges of COVID-19 pandemic: a global public health event
}

\author{
Shalmali Hui ${ }^{1}$ (D)
}

Received: 19 February 2021 / Accepted: 20 October 2021 / Published online: 3 November 2021

(c) Indian National Science Academy 2021

\begin{abstract}
COVID-19 is a highly spreadable viral infection, reported first in Wuhan, China in December 2019 which spreads worldwide later. The pathogen of this disease is SARS-CoV virus. World Health Organization announced first the name of this new disease and declared this outbreak as a Public Health Emergency of International Concern. This disaster is the most polarising global pandemic after the World War II which causes significant economic, social, political disruption, and afflicts civilization throughout human history in the world. It becomes an unprecedented challenge for India. At the time of writing this review, some specific vaccines are available but due to mutations in virus, at present it is necessary to early analyse and implement supportive treatments of this infection. Therefore, a thorough investigation is urgently required to construct an outline for the inhibition and treatment of this disease. It is necessary to understand the pathogenic mechanisms, epidemiological characteristics and to detect possible drug targets. In the present article the existing knowledge of COVID-19 including epidemiological and clinical features, available medication and treatment options till date are summarized. In addition, an up-to-date synopsis of the ongoing research progress in designing safe and effective vaccines is also highlighted which will help the human being to combat against this disease and to completely control the pandemic finally. Lastly, some major concerns to be challenged and perspectives for the future development are discussed in this article which will help to give valuable insights into new research directions.
\end{abstract}

Keywords Coronaviruses · COVID-19 $\cdot$ Outbreak $\cdot$ Clinical features $\cdot$ Therapy $\cdot$ Vaccines

\section{Introduction}

In late December 2019, in Wuhan-China, a seafood wholesale market was linked to a group of patients with pneumonia of unknown reason (Lu 2020; Hui et al. 2020; Huang et al. 2020). On January 30, 2020 this pneumonia outbreak was stated as a Public Health Emergency of International Concern by WHO. An unknown beta $(\beta)$-coronavirus as the causative pathogen was discovered using neutral sequencing in samples from patients with pneumonia (Zhu et al. 2020). On February 11, 2020 this new virus was named as SARSCov-2 by the International Committee on Taxonomy of Viruses (ICTV) and this new disease was named as COVID19 by WHO on the same day. Since the COVID-19 spreads

Shalmali Hui

mamoni06@gmail.com

1 Department of Chemistry, Hijli College Affiliated to Vidyasagar University, Kharagpur, Paschim medinipur, West Bengal 721306, India across over multiple countries throughout the world within a short span of time and the illness is severe, therefore, it is considered as a pandemic rather than only an epidemic.

Coronaviruses belong to the family Coronaviridae (order Nidovirales). These are enveloped single-strand, positivesense RNA viruses, spread generally among humans, other mammals, and birds which lead to respiratory, enteric, hepatic, and neurologic diseases (Weiss and Leibowitz 2011; Masters and Perlman 2013). The journey of human coronaviruses started in the 1960s (Kahn and Mlntosh 2005). Four coronavirus species-229E, OC43, NL63, and HKU1are prevalent out of six species (Su et al. 2016). Two other species named Severe acute respiratory syndrome coronavirus (SARS-CoV) and Middle east respiratory syndrome coronavirus (MERS-CoV) are developed from a zoonotic source which cause incurable infection (Cui et al. 2019). The beta $(\beta)$-coronaviruses are associated with severe illness and fatal disease out of four (alpha, beta, gamma and delta) coronaviruses subfamilies. On the basis of genome sequence SARS-CoV-2 belongs to $\beta$-coronaviruses and it is 
distantly correlated to SARS-CoV (Zhou et al. 2020a). It is the seventh member of the coronavirus family.

A free primitive RNA in search of stability uses parasitic relationships with the smallest unit of life, a live cell for thermodynamic stability and in this process completely suppresses the genetics of the host cell. In a word, RNA virus is always looking for a cell to invade. Once inside, it reprograms the cell with its RNA and multiplies on mass, releases several copies of the primitive RNA. These newly formed RNAs contaminate new hosts. It's desire to replicate using the biomaterials of the host cell initially becomes rapid but the defence system of the host cell starts to build the desired immunity to fight back. In this process the energy expense of the host cell and the debris of the dead cell and the RNA creates edema and side effects in the host and if the host can sustain the initial attack then it can recover after few days. But under severe trauma most of the time such attack becomes fatal and most of the time the mutated versions of the original just following the diktat of survival of the fittest. This is the basics of RNA virus attack. Firstly, SARS-CoV-2 pathogen enters to the cells via binding to a host cell's angiotensin-converting enzyme 2 (ACE2) receptors. Then it reproduces in these cells (Liu et al. 2011a). Then the new developed virions are released and contaminate new target cells.

However, at the time of writing this review some specific vaccines are now available like BNT162b2/COMIRNATY Tozinameran (INN), AZD1222, Covishield (ChAdOx1_ nCoV-19), etc. (World Health Organization 2021a) but due to mutations in virus, as of now it is necessary to control the source of infection, early diagnosis, isolation and supportive treatments (Rodriguez-Morales et al. 2020; Khan et al. 2020). To prevent the spill over of this pandemic several preventive movements including testing and treating patients, isolating, curbing huge assemblies, curfew, sustaining complete or partial lock down, surveillance and adhering strictly to lockdown procedures etc. have been taken by each and every country across the world. To avoid this infection each individual should maintain good personal sanitization and avoid crowded places. This disaster is the most polarising global pandemic after the World War II which causes significant economic, social, political disruption, and afflicts civilization throughout human history in the world.

In this current review, the existing knowledge of COVID19 to date including epidemiological and clinical features, available medication and treatment options are summarized. The main objective of this study is to provide a comprehensive framework of this newly emerged disease and to assist global researchers, clinicians \& health care providers in finding a long-term possible resolution regarding prevention and treatment of 2019-nCoV infection. In addition, this mini review aims to update the latest ongoing research progress in designing vaccines till date which will help the human being to combat against this disease, to curb the spread of this coronavirus, and to completely control the pandemic finally. Lastly, some key issues to be challenged and perspectives for the future development regarding dealing with this pandemic are discussed. Hopefully this article will help to give valuable insights into new research directions and to provide a reference for future studies of this pandemic.

\section{Structure of SARS-CoV-2}

The spike glycoproteins are present on the envelope of the coronavirus. So, it appears that the pointed structures surround the coronaviruses like a corona or crown (Fig. 1). At least 11 ORFs (Open Reading Frames) which

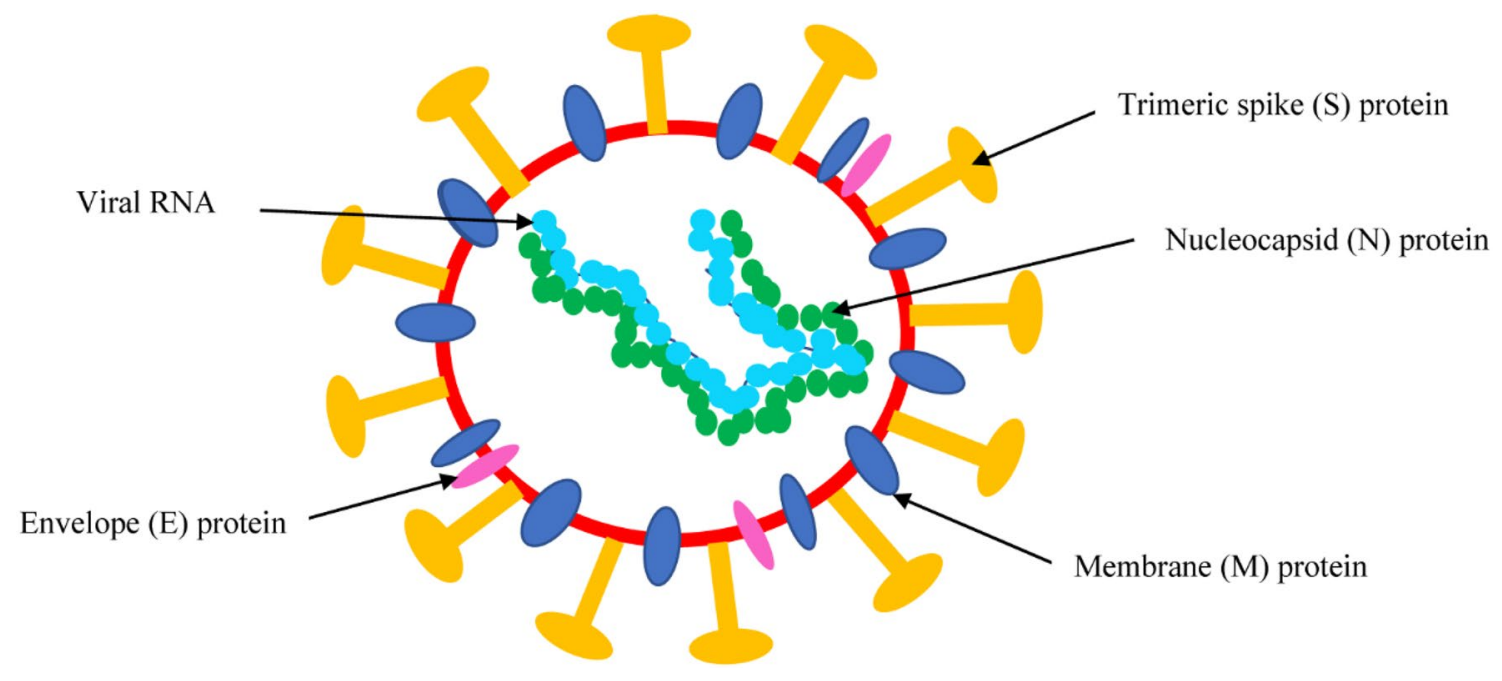

Fig. 1 Structural details of Coronavirus 
are of $\sim 29.9 \mathrm{~Kb}$ in size constitute the genetic makeup of SARS-CoV-2 (Wu et al. 2020b). Overall, $15 / 16$ proteins, 4 structural proteins and 5 accessory proteins (ORF3a, ORF6, ORF7, ORF8 and ORF9) are produced by proteolytic cleavage of polyprotein (ORF1a/b) (Ramaiah and Arumugaswami 2020; Chan et al. 2020a; Wu et al. 2020a). Its genome is similar to SARS-CoV with a gene order 5'-ORF1ab-S-E-M$\mathrm{N}-3^{\prime}$. All coronaviruses have four most important structural protein-coding genes-S (Spike protein), E (Envelope protein), M (Membrane protein) and N (Nucleocapsid protein). Among these, the spike protein $(\mathrm{S})$ is responsible both for receptor binding and membrane fusion. The $\mathrm{M}$ and $\mathrm{E}$ proteins are involved in the envelope formation of the virus while the $\mathrm{N}$ protein is involved in the assembly of the virus. For viruses, the $\mathrm{S}$ protein plays the key role to mediate coronavirus entry into host cells (Tortorici and Veesler 2019). It is the basis of viral tropism and is the main target of the humoral immune response. It is a large (approx. $180 \mathrm{kDa}$ ) 3-dimensional glycoprotein and it exists in multiple, distinct conformational states which results from $\mathrm{S}^{\mathrm{B}}$ opening at the $\mathrm{S}$ glycoprotein trimer apex (Belouzard et al. 2012; Walls et al. 2020). It has two functional domains-S1 and S2 (Belouzard et al. 2012). The $\mathrm{S} 1$ domain i.e. receptor-binding domain (RBD) region enables the receptor binding process whereas the $\mathrm{S} 2$ domain i.e. non- RBD region is responsible for fusion of the viral and cellular membranes. This S2 subdomain is the probable target for cross-reactive antibodies (Lan et al. 2020). The S1 domain has two sub units-the N-terminal subdomain (NTD) that binds sialic acid and the C-terminal subdomain that binds a specific proteinaceous receptor (Hulswit et al. 2016).

A noteworthy characteristic feature of SARS-CoV-2 genome is that it's $\mathrm{S}$ glycoprotein has an unpredicted functional polybasic furin cleavage site at the junction of $\mathrm{S} 1$ and S2 subunits via addition of a four amino acid residue (established by sequence analysis of SARS-CoV-2) (Walls et al. 2020). Furthermore, the insertion of proline at this site of this virus leads to the predicted acquisition of three O-linked glycans namely S673, T678 and S686 around the cleavage site. The existence of this inserted polybasic sequence motif sequence (PRRA) differentiates this SARS-CoV-2 S from other $\beta$-CoVs. It is processed during biosynthesis. It has a significant potential to regulate viral contamination and host range (Nao et al. 2017). Furthermore, these furin-like proteases contribute to cleave SARS-CoV-2 S protein, expand SARS-CoV-2 cell and tissue tropism, preactivate it's entry, as well as enhance it's transmissibility and/or change it's pathogenicity (Walls et al. 2020). Interestingly, in a recent study it has been observed that PRRA exhibits super-antigenic activity. Relatively less mutations are observed in this superantigen region in comparison with RBD. The sequence and structure motif of SARS-CoV-2 spike is highly similar to those of a bacterial superantigen. It may directly bind
T cell receptors (Cheng et al. 2020). Another noteworthy feature of SARS-CoV-2 is that it's S1 subunit has optimized RBD—a crucial functional constituent for binding to the human entry receptor angiotensin-converting enzyme 2 (ACE2) with a high affinity motif which supports efficient cell entry (Wan et al. 2020; Andersen et al. 2020). Six RBD amino acids namely L455, F486, Q493, S494, N501 and Y505 in SARS-CoV-2 are employed for binding to ACE2 receptors and for determining the host range of SARS-CoV-2 (Wan et al. 2020). The overall structure of the SARS-CoV-2 RBD is similar to that of the SARS-CoV RBD. Five-stranded twisted antiparallel $\beta$ sheets namely $\beta 1$, $\beta 2, \beta 3, \beta 4$ and $\beta 7$ along with helices and loops are present in the SARS-CoV-2 RBD. A prolonged addition i.e. receptor binding motif (RBM) is present in the core between the $\beta 4$ and $\beta 7$ strands which contains $\beta 5$ and $\beta 6$ strands, $\alpha 4$ and $\alpha 5$ helices and loops. This RBD has a total of nine cysteine residues. During interaction an association takes place between this extended RBM in the SARS-CoV-2 RBD and small portion of ACE2. It leads to accommodation of the N-terminal helix of the ACE2 on the external surface of the RBM. The interface between the SARS-CoV-2 RBD and ACE2 encompasses a total of 16 residues of the SARS-CoV-2 RBD along with 20 residues of ACE2. A total of $13 \mathrm{H}$-bonds and 2 salt bridges are present at this interface which lead to the formation of hydrophilic interaction networks (Lan et al. 2020). The RBD of the S1 subunit undergoes hinge-like conformational arrangements in order to encompass a host receptor (Wrapp et al. 2020; Li 2016). The prefusion trimer can be destabilised as a result of binding of the S1 subunit to a host receptor. This results in shedding of the S1 subunit after cleavage by the human proteases furin and conversion of the S2 subunit from a metastable pre-fusion into a more stable post-fusion conformation which is essential for membrane fusion (Walls et al. 2019). The antibodies which target epitopes in the RBD play an important role to develop effective therapeutic agents to combat against SARS-CoV-2 (Lan et al. 2020). Overall, a combination of the receptorbinding process and proteolytic processing of the $S$ protein is required for entry of coronavirus into vulnerable host cells.

However, to develop monoclonal antibody drugs and to guide the design and development of vaccines it is crucial to understand the structure of this novel coronavirus in details.

\section{Epidemiological characteristics of SARS-CoV-2}

\section{Progress and current status of the pandemic}

COVID-19 is a highly transmittable and pathogenic viral infection. In comparison with SARS-CoV and MERS-CoV higher number of active cases and deaths have been observed 
for COVID-19 (Wu et al. 2020c). At the time of writing this review, cases without a travel history to Wuhan is increasing considerably suggesting the possibility of human-to-human transmission (Chan et al. 2020b). Based on Johns Hopkins University statistics, the global case-fatality rate is $4.37 \%$ (Johns Hopkins University 2020. https://gisanddata.maps. arcgis.com/apps/opsdashboard/index.html\#/bda7594740 fd40299423467b48e9ecf6). However, region, time period, volume of testing, treatment options, population characteristics etc. control the death, case fatality rate and the infection fatality rate.

\section{Origin}

Although the actual origin of this novel coronavirus is still unknown, but it was assumed initially that Huanan seafood wholesale market in Wuhan, China may be the source of this virus (Zhang et al. 2020f). Initial outbreak of this pandemic from this market indicates that animal is the possible carrier of transmission of this virus to human. But at present spreading of infection among medical workers and family clusters confirm human-to-human transmission (Chan et al. 2020b). Various number of avian hosts as well as many mammals such as camels, bats, mice, dogs, cats etc. have been reported to carry coronaviruses (Cavanagh 2007; Ismail et al. 2003). Novel mammalian coronaviruses have now been often recognized (Su et al. 2016).

It has been reported that both SARS-CoV-2 and SARS$\mathrm{CoV}$ share $79.6 \%$ full-length genome sequence identity (Zhou et al. 2020a). In addition, the full-length genomesequence of SARS-CoV-2 is $96 \%$ identical to a bat coronavirus suggesting bat be the possible origin (Zhou et al. 2020a). It has been found from phylogenetic analysis that some viruses namely Bat-CoV RaTG3, Bat SARSr CoVZC45, Bat SARSr CoV-ZXC21 which are closest relatives of SARS-CoV-2 are originated from bats. Therefore, bats are supposed to be the original host of SARS-CoV-2. From these resemblances it can be stated that this new coronavirus transmits from unidentified intermediate host to humans or directly to humans. However, the presumed intermediate host remains to be recognized. In another report, it has been stated from a comprehensive sequence analysis that snake is the probably wildlife animal reservoir for the SARS-Cov-2 based on their similar codon usage bias (Ji et al. 2020). However, there is no reliable evidence that coronaviruses live in hosts other than mammals and birds (Bassetti et al. 2020). Zhang et al. have showed that at the whole genome level, Pangolin-CoV is $91.02 \%$ and $90.55 \%$ alike to SARS-CoV-2 and BatCoV RaTG13, respectively. The existence of Pangolin-CoV in dead Malayan pangolins indicates pangolin as the possible intermediate host of the SARS-CoV-2 (Zhang et al. 2020a). Many other animals may also be the probable intermediate hosts for this novel coronavirus for which further investigation is required. However, both bat $\beta$-coronaviruses and pangolin $\beta$-coronaviruses thus far have no polybasic cleavage sites. It has been reported that this polybasic cleavage site is generated by a natural development process because of the occurrence of mutations, insertions and deletions near the S1-S2 boundary (Yamada and Liu 2009). Recently, Andersen et al. have reported that SARS-CoV-2 is not a laboratory made or a persistently deployed virus via comparative analysis of genomic data (Andersen et al. 2020). They have assumed two mechanisms that can probably elucidate the origin of SARS-CoV-2: (i) selection in an animal host before zoonotic transfer; (ii) natural selection in humans following direct zoonotic transmission. In this scenario, future research should focus on generation of more data (genetic and functional) about SARS-CoV-2, evaluation of related viral sequences from diverse animal sources, recognition of possible intermediate source etc.

\section{Clinical symptoms}

The symptoms of COVID-19 infection may develop after a gestation period of 5 days (approximately) (Li et al., 2020b). The total time period from the commencement of COVID19 symptoms to decease depends on many variables like position of the patient's resistant system, their age etc. This time scale is shorter for those comorbid patients who are over 70-years old as compared to younger ones (Wang et al. 2020c) who are suffering from cardiac, diabetes, chronic respiratory disease, and cancer etc. The respiratory infections including fever, fatigue, and dry cough are the common symptoms of this disease (Cui et al. 2019; Zhu et al. 2020).

Besides these, aches and pains, nasal bottleneck, runny nose, headache, haemoptysis, diarrhoea, breathing problem, lymphopenia (Huang et al. 2020; Ren et al. 2020; Carlos et al. 2020), rhinorrhoea, myalgia, confusion, sneezing, and sore throat or sputum invention production (Assiri et al. 2013; Harapan et al. 2020; Lee et al. 2003) may appear in some cases. It has been reported that despite of being a respiratory disease COVID-19 also affects other organs and tissues. Rothan et al. have schematically reported the systemic and respiratory syndromes of this disease (Rothan and Byrareddy 2020). The virus disturbs the immune response of the body resulting in more inflammation than needed (Lei et al. 2020). It attacks kidneys leading to failure of organs ( $\mathrm{Li}$ et al. 2020c). SARS-CoV-2 can damage the kidney and testicular tissue of patients through binding to ACE2 bearing cells (Fan et al. 2021). It destroys the gastrointestinal bacteria leading to these symptoms in the digestive system (Zhang and Xu 2020). Recently, the super-antigenic activity of SARS-CoV-2 $\mathrm{S}$ glycoprotein has been reported to cause multisystem inflammatory syndrome (MIS-C) in children as well as cytokine storm in COVID-19 patients (Cheng et al. 2021). 
Severe hyperinflammatory syndrome is observed in both children and adult patients which is similar to toxic shock syndrome (TSS). These similarities clearly indicate the presence of super-antigenic fragments in SARS-CoV-2 which cause the above-mentioned disorders. This superantigen-like region of SARS-CoV-2 S binds with $\mathrm{T}$ cell receptors (TCRs) in adult COVID-19 patients and forms a ternary complex with major histocompatibility complex (MHC) class II (MHCII) molecules. T cell receptor (TCR) skewing consistent with this superantigen activation has been observed in COVID-19 patients with severe hyperinflammatory illness. Now a days the most worried report is that, in some cases, no symptom is developed in infected human body.

\section{Route of transmission of SARS-CoV-2}

SARS-CoV-2 spike binds to human ACE2 with approximately 10-20-fold higher affinity than the SARS-CoV spike (Wrapp et al. 2020) which supports human-tohuman transmission procedures reported to date. According to the recent report, COVID-19 virus is transmitted through the respiratory droplets and contact. A sick person generates the respiratory droplets through coughing, sneezing or speaking. Being too heavy to hang in the air these droplets rapidly drop on surfaces. A person can be infected by breathing in the virus if he/she is within $1 \mathrm{~m}$ of an infected person, or by touching his/her eyes, nose or mouth before washing hands. It also spreads when a person touches a virus containing surface, then touches their eyes, nose or mouth (contact transmission). This is why, it is vital to stay more than $1 \mathrm{~m}$ away from a sick person. There is also a possibility of transmission of coronaviruses through the transfusion of labile blood products. Additionally, it has been reported experimentally that the virus can persist feasible in aerosols for at least $3 \mathrm{~h}$ (Doremalen et al. 2020) and can be transmitted in closed environments if inhaled into the lungs (Adhikari et al. 2020). Therefore, airborne transmission is a possibility during aerosol generating procedures (World Health Organization 2020). In addition, SARS-CoV-2 RNA has been found in the feces of COVID-19 patients, signifying possibility of transmission of SARS-CoV-2 through the fecal-oral route (Chen et al. 2020c). Besides the respiratory tract another potential route of SARS-CoV-2 infection is the digestive tract (Zhang et al. 2020c). Since viral shedding in plasma or serum is common in upper or lower respiratory tract infections, there is a possibility of transmission of coronaviruses through the transfusion of labile blood products (Chang et al. 2020). There is also a possibility that COVID-19 can be passed on through kissing and close contact, including having sex with an infected person (Marshall 2021).

\section{Basic reproduction number $\left(R_{0}\right)$ of SARS-CoV-2}

The transmissibility of a virus is indicated by $R_{0}$. It defines the mean number of secondary cases generated by one primary case when the population is largely susceptible to infection. For an epidemic to take hold, the value of $\mathrm{R}_{0}$ must be greater than unity in value. Liu et al. have reviewed the $\mathrm{R}_{0}$ of SARS-CoV-2 and have found that the estimates range from 1.4 to 6.49, with a mean of 3.28 ( $\mathrm{Li}$ et al. 2020c) which is higher than that of SARS-CoV $\left(\mathrm{R}_{0}\right.$ of $\left.2 \sim 5\right)$.

\section{Potential therapeutic strategies against COVID-19}

Based on the earlier therapeutic experiences of SARS and MERS, the potential treatments for COVID-19 include antiviral drugs, monoclonal antibodies, plasma transfusion, cellular therapy, vaccines and so on. Primarily symptomatic treatments and antiviral therapies are the therapeutics of COVID-19. In addition to these, nutrient supplements, oxygen therapy, Chinese herbal medicine, antibacterial therapy are also essential as the supportive treatments (Wang et al. 2020d). For censoriously severe patients high-flow oxygen therapy with mechanical ventilation, extracorporeal membrane oxygenation, glucocorticoid therapy and administration of convalescent plasma are applied (Tu et al. 2020; Wei 2020).

Another strategy to treat COVID-19-associated pathologies is concentrating on repurposing broadly acting antiviral drugs used for other viral infections which is a potential therapeutic option to manage $\mathrm{CoV}$ infections, inhibit the development of illness and avoid severe disease. These antivirals prevent the viruses to enter cells and to multiply or move from infected cells to others. These drugs have certain advantages such as easy approachability, known pharmacokinetic and pharmacodynamic properties, solubility, stability, and also well-established dosing treatments (Pillaiyar et al. 2020). Although antibiotics have no role to treat COVID-19 patients, but these can be used in the case of a secondary bacterial infection. Several drugs, such as ribavirin, interferon, lopinavirritonavir, corticosteroids etc. have been applied to treat the patients with SARS or MERS. However, the efficacy of some drugs remains controversial (Zumla et al. 2016). Interestingly, use of stem cells will become a new exploration in the treatment of severe COVID-19 in future. It is expected that the stem cells will inhibit the overactivation of immune system, control acute pulmonary inflammation 
and improve the endogenous compensation for wounded tissue (Abreu et al. 2011; Silva et al. 2018).

\section{Antiviral therapy}

\section{Lopinavir/ritonavir}

Lopinavir/ritonavir, commercially known as Kaletra by AbbVie is essentially considered to treat HIV (AIDS). It has been assessed by molecular modelling study that ritonavir and lopinavir can bind to the endopeptidase $\mathrm{C} 30$ of SARS-CoV-2 protease (Lin et al. 2020). Lopinavir/ritonavir is an effective antiviral drug against SARS and MERS (Chan et al. 2003). However, no significant result on COVID-19 patients has been observed by the application of this drug, rather it results in gastrointestinal discomfort as an adverse effect (Kim et al. 2020). Chu et al. have reported that the combinational use of lopinavir, ritonavir and ribavirin gives better effect in the treatment of SARS (Chu et al. 2004). Therefore, according to the WHO, a combination of lopinavir/ritonavir with interferon- $\beta$, oseltamivir or ribavirin may give more positive results (Elfiky 2020).

\section{Interferon—alpha (IFNa)}

IFN $\alpha$ is a member of the family of type I IFNs. It plays a vital role in host resistance to viral infection. IFN $\alpha$ can efficiently avoid the reproduction of SARS-CoV (in vitro experiments) (Ströher et al. 2004; Zorzitto et al. 2006). SARS-CoV fails to attack cynomolgus monkeys when they are treated with this drug (Haagmans et al. 2004). Recently, to assess these repurposed drugs in COVID-19 a controlled trial of ritonavir boosted lopinavir and IFN $\alpha 2 b$ therapy has been documented for hospitalized patients in China (ChiCTR2000029308) (Wang et al. 2020a). So, it can be said that IFN $\alpha$ drug may play a significant role for COVID19 treatment.

\section{Favipiravir}

Using the anti-viral drug favipiravir to treat the symptoms of COVID-19 (Li et al. 2020a) has currently been approved for treating COVID-19 in China (Chu et al. 2004). Earlier this drug has been used for the treatment of Ebola, yellow fever, chikun-gunya, norovirus and enterovirus. If it is used at a high concentration [half-maximal effective concentration $(\mathrm{EC} 50)=61.88 \mu \mathrm{M}$, half-cytotoxic concentration $(\mathrm{CC} 50)>400 \mu \mathrm{M}$, selectivity index $(\mathrm{SI})>6.46]$ then it can also reduce SARS-COV-2 infection (Wang et al. 2020b).

\section{Chloroquine and hydroxychloroquine}

For the treatment of malaria, chemoprophylaxis, rheumatoid arthritis etc. Chloroquine and hydroxychloroquine drugs are generally used. According to a recent report, these drugs have been approved by the FDA to be tested against COVID-19 (Dong et al. 2020). Both drugs have in vitro action against SARS-CoV and SARS-CoV-2 (Colson et al. 2020; Keyaerts et al. 2004; Liu et al. 2020a; Shimizu et al. 1972; Wang et al. 2020b). Nevertheless, hydroxychloroquine is relatively more effective against SARS-CoV-2 (Yao et al. 2020). On the basis of these reports both drugs have received an emergency usage authorization from the FDA for the treatment of this pandemic on March 28, 2020 (Saghir et al. 2021). But recently, two largest randomized controlled trials (RCTs) data-RECOVERY (Horby et al. 2020)) and WHO SOLIDARITY (Pan et al. 2021) have confirmed no clinical advantage of CQ/HCQ regimen in COVID-19 patients. As a result, the FDA has revoked the emergency usage authorization of this regimen and it is not recommended to use in COVID-19 patients outside the framework of clinical trials (Saghir et al. 2021). Recently, Gao et al. have reported that chloroquine having anti-viral and anti-inflammatory activities is superior to the control group for destruction of COVID-19 pneumonia exacerbation, decrease of symptom duration and delay of viral clearance. Also, it does not cause any severe side effect (Gao et al. 2020a). The EC90 value of chloroquine against the 2019-nCoV in Vero E6 cells is $6.90 \mu \mathrm{M}$ and it works at both entries, and at post entry stages of the 2019-nCoV infection in these cells (Wang et al. 2020b). Besides this antiviral activity, chloroquine has also an immune-modulating activity, which may synergistically enhance its antiviral effect in vivo. It has been reported that chloroquine can cure the novel coronavirus much faster than the control group (Gao et al. 2020a). Additionally, the virus eliminating efficiency of this drug can be significantly enhanced when azithromycin is added to it (Gautret et al. 2020). Chloroquine phosphate also has a powerful activity against COVID-19. This drug is recommended by the National Health Commission of the People's Republic of China for addition in the next version of the Guidelines for the Prevention, Diagnosis, and Treatment of Pneumonia caused by COVID-19 (Gao et al. 2020a). However, both chloroquine and hydroxychloroquine have severe side effects such as deteriorating vision, sickness, digestive disorders etc. which finally lead to heart failure. So, these are never used to prevent COVID-19.

Hence, it should be used with caution before detailed evaluation of its in vitro efficiency and further clarification about COVID-19 pathogenesis (Gautret et al. 2020; Guastalegname and Vallone 2020; Gbinigie and Frie 2020). 


\section{Remdesivir}

Remdesivir is another effective drug in treating COVID-19. United States is the first country where promising result of this drug has been found (Holshue et al. 2020). It has been reported in a recent study that especially two compounds remdesivir $(\mathrm{EC} 50=0.77 \mu \mathrm{M} ; \mathrm{CC} 50>100 \mu \mathrm{M} ; \mathrm{SI}>129.87)$ and chloroquine $($ EC50 $=1.13 \mu \mathrm{M}$; CC50 $>100 \mu \mathrm{M}$, SI $>88.50$ ) are effective to strongly block virus infection at low-micromolar concentration (Wang et al. 2020b). This result indicates that its working concentration is likely to be achieved in Nonhuman Primate (NHP). Finally, it has been observed that remdesivir has a strong potential to control 2019-nCoV infection in vitro. The virus infection in a human cell line (human liver cancer Huh-7 cells) - sensitive to 2019-nCoV is inhibited by Remdesivir (Chan et al. 2020a). It has been observed that Remdesivir also inhibits virus infection efficiently in a human cell line which is sensitive to 2019-nCoV (Chan et al. 2020b). At the time of writing this review, to determine the clinical efficacy of this drug two Phase III experimental trials are continuing (NCT04252664 and NCT04257656) (Dong et al. 2020; Li and De Clercq 2020). The possible inhibition mechanism of SARS-CoV-2 RNA polymerase by Remdesivir effector molecules has been highlighted in a recent study (Gao et al. 2020b). The efficacy of remdesivir in treating COVID-19 has been further supported by another clinical trial explored by Grein et al. Here $68 \%$ clinical improvement is observed by the application of remdesivir (Grein et al. 2020).

\section{Arbidol (umifenovir)}

Another antiviral drug effective against influenza infection is Arbidol. An in vitro study states that it can be used to treat COVID-19 effectively at a concentration of 10-30 $\mu \mathrm{M}$ (Dong et al. 2020). Arbidol alone or combination with antiviral drugs is beneficial for treatment of COVID-19 patients which is supported by a retrospective cohort study, case reports and case series (Wang et al. 2020e; Zhang et al. 2020d; Xu et al. 2020).

\section{Others}

Literature survey has revealed that some other drugs also have potential to fight against COVID-19. An in vitro study has reported that Nitazoxanide - an anti-diarrhea medicine has inhibition activity of the SARS-CoV-2 (Wang et al. 2020b). In China, 95\% acute COVID-19 patients have been recovered within two weeks by application of another drug named Tocilizumab (Zhang et al. 2020f). The FDA has officially approved a phase III trial of Actemra in severe COVID-19 patients. In February 2020, it has been reported that an anti-retroviral drug Darunavir significantly prevents
SARS-CoV-2 reproduction and its inhibition efficiency (in vitro study) (Dong et al. 2020). The research team of Monash University in Melbourne, Australia has reported the noteworthy effectiveness of Ivermectin against the SARSCoV-2 virus (Caly et al. 2020). A low-dose Corticosteroids may also be advantageous for the survival of severe COVID19 patients (Chu et al. 2004; Zhou et al. 2020b). Baricitinib can also be used as a potential treatment for COVID-19 patients (Richardson et al. 2020).

It has been reported that Chinese herbal treatments are generally used for treating viral respiratory infection (Zhang et al. 2020b). Recently, in one study a combination of the antiviral or antibiotics with traditional Chinese medicines have been explored to combat against SARS-CoV-2 induced infection in humans and mice (Sheahan et al. 2020).

A joint research team of the Shanghai Institute of Materia Medica and Shanghai Tech University has reported 30 agents including indinavir, saquinavir, lopinavir, carfilzomib, ritonavir, remdesivir etc. which may also be the potential treatment options for COVID-19 due to having antiviral activity against SARS-CoV virus (Chinese Academy of Sciences 2020). A recent report has revealed that another anti-inflammatory low-cost drug Dexamethasone diminishes death by up to one-third in COVID-19 (The Indian Express 2020). The UK Government has authorized this drug against COVID-19.

Taken together, a synergistic effect of both anti-inflammatory and antiviral drugs is more beneficial for the treatment of COVID-19 rather than a single treatment. However, special consideration should be given on more experimental efficacy and safety studies before exploiting these drugs for COVID-19 patients.

\section{Immunotherapy}

\section{Convalescent plasma transfusion (CPT) therapy}

In addition to antiviral/antimicrobial drugs, another safe and clinically effective treatment for COVID-19 patients is CPT therapy which decreases mortality. It has been reported that patients who have recovered from COVID may donate convalescent plasma (CP) (Chen et al. 2020a). It has been observed that plasma of the rehabilitated patients has a significant potential to improve the conditions of patients suffering from COVID-19 (Ju et al. 2020). Rajendran et al. have done a systematic review on CPT for the treatment of COVID-19. Some significant improvements like normalization of body temperature, removal from ventilation within 1 day to maximum of 35 days post transfusion etc. are observed in COVID-19 patients after CPT therapy (Rajendran et al. 2020). Nevertheless, at present more clinical 
research should be needed to verify the safety and efficacy of CPT therapy among COVID-19 patients (Chang et al. 2020).

\section{Monoclonal antibodies}

A monoclonal antibody mimics the antibodies that are produced by the immune system of the body to fight the infection-causing microbes. It has been reported that monoclonal antibody (CR3022) binds with the spike RBD of SARSCoV-2. CR3022 alone or in combination with other neutralizing antibodies is useful for the treatment of COVID-19 infection (Tian et al. 2020). Recently, AbMax Biotechnology Co., Ltd has developed SARS-CoV-2 antibody (Yang and Wang 2020). For the treatment for cytokine release syndrome which is very common in COVID-19 patients, I-Mab Biopharma has developed another neutralizing antibody TJM. The human granulocyte-macrophage colony stimulating factor (GM-CSF) which is responsible for acute and chronic inflammation is attacked by TJM2 (ShimabukuroVornhagen et al. 2018). Rayner et al. have reported another monoclonal antibody TZLS-501 developed by Tiziana Life Sciences to treat COVID-19. TZLS-501 rapidly reduces the circulating levels of IL-6 in the blood (Rayner et al. 2020). According to a recent report, the cocktail of B38 and $\mathrm{H} 4$ antibodies has a strong potential for neutralizing the COVID-19 virus. Here both the antibodies block the binding site for the virus (Firstpost 2020). Vir Biotechnology in association with Chinese firm WuXi Biologics has tested isolated antibodies from people who survived SARS as a treatment for COVID-19. Recently, it has been reported that AbCellera has isolated 500 unique antibodies from a person who recovered from COVID-19 for testing purpose (Healthline 2020).

\section{Cellular therapy}

\section{Natural killer (NK) cells}

Recently, Natural Killer (NK) and CD8+ T cell therapy are the two most important feasible approaches for the treatment and prevention of COVID-19. NK cells are important immune cells necessary for defence against microbeinfected, stressed or malignant cells. Recently, Sorrento and Celularity has announced an allogeneic, off-the shelf, umbilical cord blood-derived NK cell therapy for the COVID-19 treatment (Diego and Warren 2020).

\section{Mesenchymal stem cells (MSCs)}

In addition, it is expected that stem cells also offer a promising approach for the treatment of COVID-19. These stem cells avoid the exaggerated immune response, control acute pulmonary inflammation and repair the damaged tissues (Abreu et al. 2011; Silva et al. 2018). A clinical trial (NCT04252118) of COVID-19 stem cell therapy sponsored by Beijing Hospital is under way at the time of writing this review.

MSCs may be used to fight against COVID-19 because these have strong anti-inflammatory and immunomodulatory properties. It has been reported that treatment with MSCs can upgrade acute/chronic lung damage and ARDS (Ortiz et al. 2007). Recently, clinical trials of MSC-based therapy in COVID-19 patients have been started in China and two trials are currently ongoing.

\section{Vaccines}

Vaccination is highly recommended due to ambiguity of clinical spectrum of virus carriers. A vaccine stimulates the immune system of the body to recognize and fight against attacking virus. Three requirements guide this vaccine effort-speed, manufacture and deployment at scale, and global access. At the time of writing this review, many drug companies, biotechnology firms, university research groups such as Pfizer-BioNTech, AstraZeneca and The University of Oxford, Serum Institute of India Pvt. Ltd., Moderna, Sinopharm/Beijing Institute of Biological Products Co-Ltd., Sinovac, Johnson \& Johnson etc. have developed COVID19 vaccines which have been finalized. Some other companies like The Gamaleya National Center, Bharat Biotech, Novavax, Sinopharm/Wuhan Institute of Biological Products Co-Ltd., CureVac, Sanofi Pasteur, Vector State Research Centre of Viralogy and Biotechnology, Zhifei LongcomChina, Clover Biopharmaceuticals, and BioCubaFarmaCuba etc. are still working for the development of effective SARS-CoV-2 vaccines (World Health Organization 2021a). However, this virus has genetic instability and it is mutating at a very high speed. Therefore, it is very difficult for the scientists to discover the appropriate vaccine for COVID19. Genomic sequence studies have established that spike protein of SARS-CoV-2 is identical with that of SARS and MERS. Therefore, it clearly indicates that the immune evasion mechanism of SARS-CoV-2, SARS and MERS might be similar (Shanmugaraj et al. 2020a; Shanmugaraj et al. 2020b). It has been reported by Yu et al. that the most promising candidate $\mathrm{CoV}$ vaccine composition is the full-length or appropriate parts of the $\mathrm{S}$ glycoprotein because the most variable residues are located in the $\mathrm{S} 1$ subunit of S proteinthe critical CoV vaccine target (Yu et al. 2020).

Recently, the Coalition for Epidemic Preparedness Innovations (CEPI) along with Inovio, The University of Queensland, Moderna, Inc. and the U.S. National Institute of Allergy and Infectious Diseases (NIAID) has initiated three programmes to develop vaccines against the SARS-CoV-2 
(CEPI 2020). Airway Therapeutics has developed AT-100, a recombinant form of human surfactant protein-D (rhSPD) for the treatment of COVID-19. AT-100 helps to reduce irritation and contamination in the lungs. It also generates an immune response against various respiratory diseases (Crouch 2000). Another vaccine ChAdOx1 nCoV-19 has been developed jointly by the University of Oxford's Jenner Institute and Italian pharmaceutical manufacturer Advent Srl. It consists of an attenuated adenovirus to deliver the spike (S) protein of SARS-CoV-2, leads to the formation of endogenous antibodies against these proteins and, consequently induces a protective immune response against SARS-CoV-2 (Alharbi et al. 2017). The process is now under investigation. Pune based Serum Institute of India will start manufacturing of this vaccine if the Phase- 1 trial results are encouraging. NIAID-VRC scientists are developing a vaccine candidate expressing SARS-CoV-2 S protein in the mRNA vaccine platform technology. This vaccine is expected to undergo clinical testing in the coming months (NIAID 2020). Bacillus Calmette-Guérin (BCG) is an effective vaccine against tuberculosis. It has been reported that a recombinant vaccine strain named VPM1002, derived from BCG, can protect either health-care workers or older patients from COVID-19 (de Vrieze 2020). It has been suggested by the researchers that bisphosphonates might activate a vaccine against SARS-CoV-2 and induce immunity to huge populations more quickly (Medicalxpress News, 2020). After safety assessment in monkeys, Avian IBV vaccine may be another suitable treatment option for COVID19 (Zhang and Liu 2020). mRNA-based vaccine's sample (prepared by Stermirna Therapeutics) will be available soon (XINHUANET 2020). Chinese Centre for Disease Control and Prevention (CDC) is working on the development of an inactivated virus vaccine (Jeong-ho et al. 2020; Cheung 2020). GeoVax-BravoVax is working to develop a Modified Vaccina Ankara (MVA) based vaccine (Geo-Vax 2020). A recombinant 2019-nCoV S protein subunit-trimer based vaccine is developed by Clover Biopharmaceuticals (Clover 2020). German biotech firm CureVac has started human trials of its coronavirus vaccines after getting approval from regulators. Moscow-based Gamaleya research institute has developed two forms of a vaccine-liquid and powder. In Russia experimental trials of this vaccine have been initiated (The Indian Express 2020). The pharmaceutical companies Johnson \& Johnson and Sanofi are both working on a vaccine of their own by growing viral proteins in cell cultures. The polio vaccine may be another possible option to fight against COVID-19 which might increase the immune system (Chang et al. 2020). Another vaccine COVAX-19 has been developed by Vaxine Private Limited using unique Advax (TM) technology. Imperial College London has started clinical trials of their own vaccine. Here synthetic code of the SARS-CoV-2's genetic material has been used to modify the immune system's response (Times of India 2020). Besides these, many other vaccine candidates namely Covid-19/ aAPC by Shenzhen Genoimmune Medical Institute, LVSMENP-DC by Shenzhen Genoimmune Medical Institute, bacTRL-Spike by Symvivo Corporation etc. are undergoing clinical evaluation. Recently, a detailed study about COVID19 vaccines has been explored briefly by Forni et al. (Forni and Mantovani 2021) where development of over 300 vaccine projects has been reported which may be helpful in protecting individuals and reducing the spread of pandemic. They have highlighted the ongoing projects of attenuated SARS-CoV-2 vaccines (three vaccine candidates), vaccines based on the inactivated SARS-CoV-2 viruses (seven vaccine candidates), vaccines based on SARS-CoV-2 proteins (sixteen vaccine candidates), naked DNA-based vaccines (six vaccine candidates), mRNA-based vaccines (twelve vaccine candidates), and vaccines based on viral vectors. It is essential to focus on competitive therapeutic options and cross-resistance of other vaccines in order to get a broad spectrum. However, in addition to the aforementioned protective and beneficial measures, more tremendous efforts are also required to concentrate on psychological interventions in order to control this infection (Chen et al. 2020b).

Finally, 108 vaccines have been reported to be in clinical development and 184 vaccines in pre-clinical development (World Health Organization 2021b). India's first indigenous COVID-19 vaccine is COVAXIN ${ }^{\mathrm{TM}}$ — jointly developed by ICMR, Bharat Biotech India Limited and National Institute of Virology (NIV) (Bharat Biotech 2020). Whole-Virion Inactivated Vero Cell derived platform technology is utilized to develop this vaccine. On January 03, 2021 this vaccine has been approved in India for emergency restricted use by DCGI-CDSCO. Moderna's $m R N A-1273$ vaccine is one of the most important vaccines which uses a synthetic lipid nanoparticle to carry mRNA templates. It translates the prefusion stabilized full-length spike protein of the SARS$\mathrm{CoV}-2$. Another one is BNT162b2 developed by BioNTech and Pfizer. It is a lipid nanoparticle-formulated, nucleoside modified RNA vaccine which translates SARS-CoV-2 full-length spike protein. In the UK, Europe and the US, both vaccines are currently approved and recommended to prevent COVID-19. The University of Oxford and AstraZeneca have developed another recombinant vaccine called AZD1222 (formerly known as ChAdOx1 nCoV-19). It has been approved in the UK and Europe. Besides these three, Sputnik V developed by Gamaleya Research Institute, Acellena Contract Drug Research and Development, CoronaVac by Sinovac, BBIBP-CorV by Beijing Institute of Biological Products; China National Pharmaceutical Group (Sinopharm), EpiVacCorona by Federal Budgetary Research Institution State Research Center of Virology and Biotechnology, Convidicea (Ad5-nCoV) by CanSino Biologics, INO-4800a DNA based vaccine by Inovio Pharmaceuticals, another 
vaccine yet to be named developed by Wuhan Institute of Biological Products; China National Pharmaceutical Group (Sinopharm) have been approved (Mullard 2020; Craven 2021). JNJ-78436735 (formerly Ad26.COV2-S) owned by Johnson \& Johnson, and NVX-CoV2373 vaccine developed by Novavax are now in the approval stage (Gallagher 2021). In addition, to produce a stronger immune response a mix-and-match vaccination treatment by combining both the Oxford/AstraZeneca and the Pfizer/BioNTech vaccine is ongoing by UK vaccine task force (Boseley 2020). Besides these, 56 more vaccines candidates are now under development (Craven 2021).

\section{Current challenges, future perspectives and conclusion}

Currently, COVID-19 creates a serious global public health threat. This disaster is disrupting every aspect of life in terms of distressing economic, social, and political emergency; crumpling of healthcare structures; damaging immune systems; and afflicting civilization throughout human history in the world. Considering all these aspects investigation, diagnostics, clinical therapy, research \& development of vaccines and drugs are required immediately to prevent this disease. In this present article, we have surveyed the existing knowledge of COVID-19 including epidemiological and clinical features, available medication and treatment options till date. In addition, an up-to-date summary of the ongoing research progress in designing safe and effective vaccines has also been emphasized which will help the human being to combat against this disease, to curb the spread of this coronavirus, and to completely control the pandemic finally.

At this point of time, it is indispensable to control the source of disease, cut off the transmission path, follow a safety principle, and use the existing drugs and means to control the progress of the disease proactively and to reduce fatality rate as well. A great deal of effort on possible therapies with minimal side effects is going on worldwide to cope with this novel coronavirus. In the last few months, considerable development has been made in clinical treatment such as repurposing of existing drug candidates, exploring synergistic effect of two or more drugs, designing of new drugs etc. which has opened new avenues for prevention, diagnosis, and treatment of this disease. Similarly, extensive research work is going on side by side all over the world for developing vaccines. Globally by July 2021, a good number of vaccines has been finalized and approved as well, whereas a good number of candidates are under study (different stages of preclinical and clinical research) and expected to be launched as soon as possible.

However, the full impact of COVID-19 on human health has yet to be known because of some critical issues and limitations. The most critical issue is the mutation of this novel virus due to which fabrication of suitable vaccine still remains a difficult challenge. Nowadays it has become a great challenge to the researchers to fix this problem and halt this deadly infection. Keeping this in mind, the future research should focus on the fabrication and development of new antiviral drugs, more potent vaccines, and more well-designed clinical trials of these on a large number of subjects in an economically viable way to confirm their effectiveness and safety before commercialization. It will help to minimize the risks to human health as well as environment. Meanwhile, in future we need multidimensional approaches to deal with this pandemic. Above all, each and every individual has to maintain a personal protection hygiene to prevent the transmission of this virus. However, at present sufficient data is not yet available. Therefore, special consideration should be given on developing and implementing more effective and accurate technological strategies to collect precise data on diverse therapeutic approaches for this disease. The formulation of a standardized framework, a clear guideline and the possible suitable safety measures are needed to be developed on an urgent basis. This will assist to systematically detect, characterize and control this disease; analyse its long-term health effect for human beings; categorize its associated risks; optimize the risk factors and the healthcare amenities. Significant efforts should be expanded to implement mass vaccination programme worldwide which is one of the most preventive strategies to prevent this viral infection.

Therefore, to meet the above-mentioned challenges more scientific investigations need to be undertaken immediately for a systematic and long-term study on COVID19. It is of paramount importance to take the combined efforts of all the governments, health authorities, scientific communities and manufacturer sectors throughout the world. It will provide a combined solution in terms of establishing an effective outbreak response system, potential therapeutic treatments and vaccines to eventually diminish this pandemic, and to prevent future wave of related new and re-emerging infectious diseases. We expect that aforementioned current challenges and perspectives for the future development of COVID-19 will help researchers and health care providers to give valuable insights into new research directions.

Funding This research did not receive any specific grant from funding agencies in the public, commercial, or not-for-profit sectors.

Availability of data and material Not applicable.

Code availability Not applicable. 


\section{Declarations}

Conflicts of interest The author declares that she has no conflict of interest.

\section{References}

Abreu, S.C., Antunes, M.A., Pelosi, P., Morales, M.M., Rocco, P.R.: Mechanisms of cellular therapy in respiratory diseases. Intensive Care Med. 37(9), 1421-1431 (2011)

Adhikari, S.P., Meng, S., Wu, Y.J., Mao, Y.P., Ye, R.X., Wang, Q.Z., et al.: Epidemiology, causes, clinical manifestation and diagnosis, prevention and control of coronavirus disease (COVID19) during the early outbreak period: a scoping review. Infect. Dis. Poverty 9(1), 1-12 (2020). https://doi.org/10.1186/ s40249-020-00646-X

Alharbi, N.K., Regalado, E.P., Thompson, C.P., Kupke, A., Wells, D., Sloan, M.A., et al.: ChAdOx1 and MVA based vaccine candidates against MERS-CoV elicit neutralising antibodies and cellular immune responses in mice. Vaccine 35(30), 3780-3788 (2017)

Andersen, K.G., Rambaut, A., Lipkin, W.I., Holmes, E.C., Garry, R.F.: The proximal origin of SARS-CoV-2. Nat. Med. 26, 450-455 (2020)

Assiri, A., Al-Tawfiq, J.A., Al-Rabeeah, A.A., Al-Rabiah, F.A., AlHajjar, S., AlBarrak, A., et al.: Epidemiological, demographic, and clinical characteristics of 47 cases of Middle East respiratory syndrome coronavirus disease from Saudi Arabia: a descriptive study. Lancet Infect. Dis. 13(9), 752-761 (2013). https://doi.org/ 10.1016/S1473-3099(13)70204-4

Bassetti, M., Vena, A., Giacobbe, D.R.: The novel Chinese coronavirus (2019-nCoV) infections: challenges for fighting the storm. Eur. J. Clin. Investig. 50(3), e13209 (2020). https://doi.org/10.1111/ eci.13209p.e13209

Belouzard, S., Millet, J.K., Licitra, B.N., Whittaker, G.R.: Mechanisms of coronavirus cell entry mediated by the viral spike protein. Viruses 4, 1011-1033 (2012)

Bharat Biotech (2020) COVAXIN ${ }^{\mathrm{TM}}$ _ India's first indigenous COVID19 vaccine. https://www.bharatbiotech.com/covaxin.html. Accessed 01b Feb 2021

Boseley S (2020) UK trial to mix and match Covid vaccines to try to improve potency. The Guardian. https://www.theguardian.com/ world/2020/dec/08/covid-mixed-vaccine-trial-likely-tobegin-inuk-next-month. Accessed 08 Dec 2020

Caly, L., Druce, J.D., Catton, M.G., Jans, D.A., Wagstaff, K.M.: The FDA-approved drug Ivermectin inhibits the replication of SARSCoV-2 in vitro. Antivir. Res. 178, 104787 (2020). https://doi.org/ 10.1016/j.antiviral.2020.104787

Carlos, W.G., Dela Cruz, C.S., Cao, B., Pasnick, S., Jamil, S.: COVID19 disease due to SARS- CoV-2 (Novel Coronavirus). Am. J. Respir. Crit. Care Med. 201(4), 7-8 (2020). https://doi.org/10. 1164/rccm.2014P7

Cavanagh, D.: Coronavirus avian infectious bronchitis virus. Vet. Res. 38, 281-297 (2007)

CEPI: CEPI to fund three programmes to develop vaccines against the novel coronavirus, nCoV-2019. CEPI. https://cepi.net/news_cepi/ cepi-to-fund-three-programmes-todevelop-vaccines-against-thenovel-coronavirus-ncov-2019/. Accessed 15 Feb 2020 (2020)

Chan, K.S., Lai, S.T., Chu, C.M., Tsui, E., Tam, C.Y., Wong, M.M.L., et al.: Treatment of severe acute respiratory syndrome with lopinavir/ritonavir: a multicentre retrospective matched cohort study. Hong Kong Med J 9(6), 399-406 (2003)
Chan, J.F., Kok, K.H., Zhu, Z., Chu, H., To, K.K.W., Yuan, S., et al.: Genomic characterization of the 2019 novel human-pathogenic coronavirus isolated from a patient with atypical pneumonia after visiting Wuhan. Emerg. Microbes Infect. 9, 221-236 (2020a). https://doi.org/10.1080/22221751.2020.1719902

Chan, J.F., Yuan, S., Kok, K.H., To, K.K., Chu, H., Yang, J., et al.: A familial cluster of pneumonia associated with the 2019 novel coronavirus indicating personto-person transmission: a study of a family cluster. Lancet 395, 514-523 (2020b). https://doi. org/10.1016/S0140-6736(20)30154-9

Chang, L., Yan, Y., Wang, L.: Coronavirus disease 2019: coronaviruses and blood safety. Transfus. Med. Rev. 34(2), 75-80 (2020). https://doi.org/10.1016/j.tmrv.2020.02.003

Chen, L., Xiong, J., Bao, L., Shi, Y.: Convalescent plasma as a potential therapy for COVID-19. Lancet Infect. Dis. 20(4), 398-400 (2020a)

Chen, Q., Liang, M., Li, Y., Guo, J., Fei, D., Wang, L., et al.: Mental health care for medical staff in China during the COVID-19 outbreak. Lancet 7, 15-16 (2020b). https://doi.org/10.1016/ S2215-0366(20)30078-X

Chen, Y., Chen, L., Deng, Q., Zhang, G., Wu, K., Ni, L., et al.: The presence of SARD-CoV-2 RNA in the feces of COVID-19 patients. J. Med. Virol. 92, 833-840 (2020c)

Cheng, M.H., Zhang, S., Porritt, R.A., Rivas, M.N., Paschold, L., Willscher, E., et al.: Superantigenic character of an insert unique to SARS-CoV-2 spike supported by skewed TCR repertoire in patients with hyperinflammation. PNAS 117(41), 25254-25262 (2020)

Cheung, E.: China coronavirus: Hong kong researchers have already developed vaccine but need time to test it, expert reveals. South china morning post. https://www.scmp.com/news/hongkong/ health-environment/article/3047956/chinacoronavirus-hongkong-researchers-have. Accessed 28 Jan 2020 (2020)

China fast-tracks novel coronavirus vaccine development. XINHUANET. http://www.xinhuanet.com/english/2020-01/28/c_13873 9378.htm. Accessed 28 Jan 2020

Chu, C.M., Cheng, V.C., Hung, I.F.N., Wong, M.M.L., Chan, K.H., Chan, K.S., et al.: Role of lopinavir/ritonavir in the treatment of SARS: initial virological and clinical findings. Thorax 59(3), 252-256 (2004)

Clover, B: Clover initiates development of recombinant subunittrimer vaccine for wuhan coronavirus (2019-ncov). http:// www.cloverbiopharma.com/index.php? $\mathrm{m}=$ content \&c $=$ index $\& a=$ show \&catid $=11 \& i d=40$. Accessed 6 Mar 2020 (2020)

Colson, P., Rolain, J.M., Lagier, J.C., Brouqui, P., Raoult, D.: Chloroquine and hydroxychloroquine as available weapons to fight COVID-19. Int. J. Antimicrob. Agents 55(4), 105932 (2020). https://doi.org/10.1016/j.ijantimicag.2020.105932

Coronavirus (Covid-19) vaccine status check: CureVac starts human trials; Pfizer vaccine by October. The Indian Express. https:// indianexpress.com/article/coronavirus/coronavirus-covid19-vaccine-curevac-sinopharm-pfizer-moderna-status-check6464868/. Accessed 19 June 2020

Coronavirus Vaccine Update: From Life-Saving Dexamethasone, Oxford Vaccine Guaranteeing Protection and Phase 1 Of Ferret Studies, Here Are All the Updates. Times of India. https://m. timesofindia.com/life-style/health-fitness/health-news/coron avirus-vaccine-update-from-life-saving-dexamethasone-tooxford-vaccine-guaranteeing-protection-here-are-all-the-updat es/amp_etphotostory/76446099.cms\#aoh=15925639787617\& referrer=https\%3A\%2F\%2Fwww.google.com\&amp_tf=From\% $20 \% 251 \% 24$ s. Accessed 19 June 2020

Craven, J.: COVID-19 vaccine tracker. https://www.raps.org/newsand-articles/news-articles/2020/3/covid-19-vaccine-tracker. Accessed 13 Feb 2021 (2021) 
Crouch, E.C.: Surfactant protein-D and pulmonary host defense. Respir. Res. 1(2), 93-108 (2000)

Cui, J., Li, F., Shi, Z.L.: Origin and evolution of pathogenic coronaviruses. Nat. Rev. Microbiol. 17, 181-192 (2019). https://doi.org/ 10.1038/s41579-018-0118-9

de Vrieze, J.: Can a century-old TB vaccine steel the immune system against the new coronavirus? Science. https://www.sciencemag. org/news/2020/03/can-century-old-tb-vaccine-steel-immunesyst em-against-new-coronavirus\#. Accessed 23 Mar 2020 (2020)

Diego, S., Warren, N.J.: Sorrento and Celularity to initiate emergency allogeneic natural killer (NK) cell therapy development for coronavirus infection. https://seekingalpha.com/pr/17762358-sorre nto-and-celularity-to-initiate-emergency-allogeneic-naturalkil ler-nk-cell-therapy. Accessed 29 Jan 2020 (2020)

Dong, L., Hu, S., Gao, J.: Discovering drugs to treat coronavirus disease 2019 (COVID-19). Drug Discov. Ther. 14(1), 58-60 (2020)

Doremalen, V.N., Bushmaker, T., Morris, D.H., Holbrook, M.G., Gamble, A., Williamson, B.N., et al.: Aerosol and surface stability of SARS-CoV-2 as compared with SARS-CoV-1. N. Engl. J. Med. 382, 1564-1567 (2020). https://doi.org/10.1056/NEJMc2004973

Elfiky, A.A.: Anti-HCV, nucleotide inhibitors, repurposing against COVID-19. Life Sci 248, 117477 (2020). https://doi.org/10. 1016/j.1fs.2020.117477

Fan, C., Lu, W., Li, K., Ding, Y., Wang, J.: ACE2 expression in kidney and testis may cause kidney and testis damage after 2019-nCoV infection. MedRxiv (2021). https://doi.org/10.1101/2020.02.12. 20022418

Forni, G., Mantovani, A.: COVID-19 vaccines: where we stand and challenges ahead. Cell Death Differ 28, 626-639 (2021)

Gallagher, J.: Covid vaccine update: those that work - and the others on the way. BBC NEWS. https://www.bbc.com/news/amp/health51665497. Accessed 02 Feb 2021 (2021)

Gao, J., Tian, Z., Yang, X.: Breakthrough: Chloroquine phosphate has shown apparent efficacy in treatment of COVID-19 associated pneumonia in clinical studies. Biosci. Trends 14(1), 72-73 (2020a)

Gao, Y., Yan, L., Huang, Y., Liu, F., Zhao, Y., Cao, L., et al.: Structure of RNA-dependent RNA polymerase from 2019-nCoV, a major antiviral drug target. BioRxiv (2020b). https://doi.org/10.1101/ 2020.03.16.993386

Gautret, P., Lagier, J.C., Parola, P., Hoang, V.T., Meddeb, L., Mailhe, M., et al.: Hydroxychloroquine and azithromycin as a treatment of COVID-19: results of an open-label non-randomized clinical trial. Int. J. Antimicrob. Agents (2020). https://doi.org/10.1016/j. ijantimicag.2020.105949

Gbinigie, K., Frie, K.: Should chloroquine and hydroxychloroquine be used to treat COVID-19? A rapid review. BJGP 4(2), bjgpopen20X101069 (2020). https://doi.org/10.3399/bigpopen20 X101069

Geo-Vax: Geovax and bravovax (wuhan, china) to collaborate on development of coronavirus vaccine. Geo-Vax. https://www. geovax.com/news/geovax-and-bravovax-wuhan-china-to-colla borateondevelopment-of-coronavirus-vaccine. Accessed 27 Jan $2020(2020)$

Grein, J., Ohmagari, N., Shin, D., Diaz, G., Asperges, E., Castagna, A., et al.: Compassionate use of remdesivir for patients with severe Covid-19. N. Engl. J. Med. 382(24), 2327-2336 (2020)

Guastalegname, M., Vallone, A.: Could chloroquine /hydroxychloroquine be harmful in Coronavirus disease 2019 (COVID-19) treatment? Clin. Infect. Dis. 71(15), 888-889 (2020). https://doi. org/10.1093/cid/ciaa321

Haagmans, B.L., Kuiken, T., Martina, B.E., Fouchier, R.A., Rimmelzwaan, G.F., van Amerongen, G., et al.: Pegylated interferon- $\alpha$ protects type 1 pneumocytes against SARS coronavirus infection in macaques. Nat. Med. 10, 290-293 (2004)
Harapan, H., Itoh, N., Yufika, A., Winardi, W., Keam, S., Te, H., Megawati, D., Hayati, Z., Wagner, A.L., Mudatsir, M.: Coronavirus disease 2019 (COVID-19): a literature review. J. Infect. Public Health 13, 667-673 (2020)

Here's Exactly Where We Are with Vaccines and Treatments for COVID-19. Healthline. https://www.healthline.com/health-news/ heres-exactly-where-were-at-with-vaccines-and-treatments-forcovid-19\#Other-treatments. Accessed 15 June 2020

Holshue, M.L., DeBolt, C., Lindquist, S., Lofy, K.H., Wiesman, J., Bruce, H., et al.: First case of 2019 novel Coronavirus in the United States. N. Engl. J. Med. 382, 929-936 (2020)

Horby, P., Mafham, M., Linsell, L., Bell, J.L., Staplin, N., Emberson, J.R., et al.: Effect of hydroxychloroquine in hospitalized patients with Covid-19. N. Engl. J. Med. 383, 2030-2040 (2020)

Huang, C., Wang, Y., Li, X., Ren, L., Zhao, J., Hu, Y., et al.: Clinical features of patients infected with 2019 novel coronavirus in Wuhan, China. Lancet 395, 497-506 (2020). https://doi.org/10. 1016/S0140-6736(20)30183-5

Hui, D.S., Azhar, E.I., Madani, T.A., Ntoumi, F., Kock, R., Dar, O., et al.: The continuing 2019-nCoV epidemic threat of novel coronaviruses to global health-the latest 2019 novel coronavirus outbreak in Wuhan, China. Int. J. Infect. Dis. 91, 264-266 (2020)

Hulswit, R.J., de Haan, C.A., Bosch, B.J.: Coronavirus spike protein and tropism changes. Adv Virus Res 96, 29-57 (2016)

Ismail, M.M., Tang, A.Y., Saif, Y.M.: Pathogenicity of turkey coronavirus in turkeys and chickens. Avian Dis. 47, 515-522 (2003)

Jeong-ho, L., Zheng, W., Zhou, L.: Chinese scientists race to develop vaccine as coronavirus death toll jumps. South China Morning Post. https://www.scmp.com/news/china/society/article/3047676/ numbercoronavirus-cases-chinadoubles-spread-rate-accelerates. Accessed 26 Jan 2020 (2020)

Ji, W., Wang, W., Xiaofang, Z., Zhao, X., Zai, J., Li, X.: Homologous recombination within the spike glycoprotein of the newly identified coronavirus may boost cross-species transmission from snake to human. J. Med. Virol. 92(4), 433-440 (2020). https:// doi.org/10.1002/jmv.26048

Johns Hopkins University: COVID-19 Dashboard by the Centre for Systems Science and Engineering (CSSE) at Johns Hopkins University (JHU) ArcGIS. https://gisanddata.maps.arcgis.com/ apps/opsdashboard/index.html\#/bda7594740fd40299423467b4 8e9ecf6 (2020)

Ju, B., Zhang, Q., Ge, J., Wang, R., Sun, J., Ge, X., et al.: Human neutralizing antibodies elicited by SARS-CoV-2 infection. Nature 584, 115-119 (2020)

Kahn, J.S., Mlntosh, K.: History and recent advances in coronavirus discovery. Pediatric Infect. Dis. J. 24, S223-S227 (2005)

Keyaerts, E., Vijgen, L., Maes, P., Neyts, J., Van Ranst, M.: In vitro inhibition of severe acute respiratory syndrome coronavirus by chloroquine. Biochem. Biophys. Res. Commun. 323(1), 264-268 (2004)

Khan, S., Siddique, R., Ali, A., Xue, M., Nabi, G.: Novel coronavirus, poor quarantine, and the risk of pandemic. J. Hosp. Infect. 104(4), 449-450 (2020)

Kim, J.Y., Ko, J.H., Kim, Y., Kim, Y.J., Kim, J.M., Chung, Y.S., et al.: Viral load kinetics of SARS-CoV-2 infection in first two patients in Korea. J. Korean Med. Sci. 35(7), 86 (2020)

Lan, J., Ge, J., Yu, J., Shan, S., Zhou, H., Fan, S., et al.: Structure of the SARS-CoV-2 spike receptor-binding domain bound to the ACE2 receptor. Nature 581, 215-220 (2020)

Lee, N., Hui, D., Wu, A., Chan, P., Cameron, P., Joynt, G.M., et al.: A major outbreak of severe acute respiratory syndrome in Hong Kong. N. Engl. J. Med. 348(20), 1986-1994 (2003)

Lei, J., Li, J., Li, X.: CT imaging of the 2019 novel Coronavirus (2019nCoV) pneumonia. Radiology 295(1), 18 (2020). https://doi.org/ 10.1148/radiol.2020200236 
Li, F.: Structure, function, and evolution of coronavirus spike proteins. Annu. Rev. Virol. 3, 237-261 (2016)

Li, G., De Clercq, E.: Therapeutic options for the 2019 novel coronavirus (2019-nCoV). Nat. Rev. Drug Discov. 19(3), 149-150 (2020)

Li, H., Wang, Y.M., Xu, J.Y., Cao, B.: Potential antiviral therapeutics for 2019 Novel Coronavirus, Chinese. J. Tuberc. Respir. Dis. 43(3), 170-172 (2020a)

Li, Q., Med, M., Guan, X., Wu, P., Wang, X., Zhou, L., Tong, Y., et al.: Early transmission dynamics in Wuhan, China, of novel coronavirus-infected pneumonia. N. Engl. J. Med. 382, 1199-1207 (2020b). https://doi.org/10.1056/NEJMoa2001316

Li, Z., Wu, M., Yao, J., Guo, J., Liao, X., Song, S., et al.: Caution on kidney dysfunctions of 2019-nCoV patients. MedRxiv (2020c). https://doi.org/10.1101/2020.02.08.20021212

Lin, S., Shen, R., Guo, X.: Molecular modeling evaluation of the binding abilities of ritonavir and lopinavir to Wuhan pneumonia coronavirus proteases. BioRxiv (2020). https://doi.org/10.1101/ 2020.01.31.929695

Liu, L., Wei, Q., Alvarez, X., Wang, H., Du, Y., Zhu, H., et al.: Epithelial cells lining salivary gland ducts are early target cells of severe acute respiratory syndrome coronavirus infection in the upper respiratory tracts of rhesus macaques. J. Virol. 85(8), 4025-4030 (2011)

Liu, J., Cao, R., Xu, M., Wang, X., Zhang, H., Hu, H., Li, Y., Hu, Z., Zhong, W., Wang, M.: Hydroxychloroquine, a less toxic derivative of chloroquine, is effective in inhibiting SARS-CoV-2 infection in vitro. Cell Discov. 6(1), 16 (2020a). https://doi.org/10. 1038/s41421-020-0156-0

Liu, Y., Gayle, A.A., Wilder-Smith, A., Rocklöv, J.: The reproductive number of COVID-19 is higher compared to SARS coronavirus. J. Travel Med. 27(2), 21 (2020b). https://doi.org/10.1093/jtm/ taaa021

Lu, H.: Outbreak of pneumonia of unknown etiology in Wuhan China: the mystery and the miracle. J. Med. Virol. 92(4), 401-402 (2020)

Marshall, W.F.: Sex and coronavirus: can you get COVID-19 from sexual activity? https://www.mayoclinic.org/diseases-conditions/ coronavirus/expert-answers/sex-and-coronavirus/faq-20486572. Accessed 18 May 2021 (2021)

Masters, P.S., Perlman, S.: Coronaviridae. In: Knipe, D.M., Howley, P.M. (eds.) Fields virology, 6th edn., pp. 825-858. Lippincott Williams \& Wilkins (2013)

Mullard, A.: COVID-19 vaccine development pipeline gears up. Lancet 395(10239), 1751-1752 (2020). https://doi.org/10.1016/S01406736(20)31252-6

Nao, N., Yamagishi, J., Miyamoto, H., Igarashi, M., Manzoor, R., Ohnuma, M., et al.: Genetic predisposition to acquire a polybasic cleavage site for highly pathogenic avian influenza virus hemagglutinin. Mbio 8(1), e02298-e2316 (2017)

NIAID: Developing therapeutics and vaccines for coronaviruses. NIAID. https://www.niaid.nih.gov/diseasesconditions/coron aviruses-therapeutics-vaccines. Accessed 15 Feb 2020 (2020)

Ortiz, L.A., Dutreil, M., Fattman, C., Pandey, A.C., Torres, G., Go, K., et al.: Interleukin 1 receptor antagonist mediates the antiinflammatory and antifibrotic effect of mesenchymal stem cells during lung injury. Proc Natl Acad Sci USA 104, 11002-110027 (2007)

Pan, H., Peto, R., Henao-Restrepo, A.M., Preziosi, M.P., Sathiyamoorthy, V., Karim, Q.A., et al.: Repurposed antiviral drugs for COVID-19; interim WHO solidarity trial results. N. Engl. J. Med. 384, 497-511 (2021)

Pillaiyar, T., Meenakshisundaram, S., Manickam, M.: Recent discovery and development of inhibitors targeting coronaviruses. Drug Discov. Today 25(4), 668-688 (2020)

Rajendran, K., Narayanasamy, K., Rangarajan, J., Rathinam, J., Natarajan, M., Ramachandran, A.: Convalescent plasma transfusion for the treatment of COVID19: systematic review. J. Med. Virol. 92(9), 1475-1483 (2020)

Ramaiah, A., Arumugaswami, V.: Insights into cross-species evolution of novel human coronavirus 2019-nCoV and defining immune determinants for vaccine development. BioRxiv (2020). https:// doi.org/10.1101/2020.01.29.925867

Rayner, C.R., Smith, P.F., Hershberger, K., Wesche, D., et al.: Optimizing COVID-19 candidate therapeutics: thinking Without Borders. Clin. Transl. Sci. (2020). https://doi.org/10.1111/cts.12790

Ren, L.L., Wang, Y.M., Wu, Z.Q., Xiang, Z.C., Guo, L., Xu, T., et al.: Identification of a novel coronavirus causing severe pneumonia in human: a descriptive study. Chin. Med. J. 133(9), 1015-1024 (2020). https://doi.org/10.1097/CM9.0000000000000722

Richardson, P., Griffin, I., Tucker, C., Smith, D., Oechsle, O., Phelan, A., et al.: Baricitinib as potential treatment for 2019-nCoV acute respiratory disease. Lancet 395(10223), e30 (2020)

Rodriguez-Morales, A.J., Bonilla-Aldana, D.K., Tiwari, R., Sah, R., Rabaan, A.A., Dhama, K.: COVID-19, an emerging coronavirus infection: current scenario and recent developments-an overview. J. Pure Appl. Microbiol. 14(1), 5-12 (2020)

Rothan, H.A., Byrareddy, S.N.: The epidemiology and pathogenesis of coronavirus disease (COVID-19) outbreak. J. Autoimmun. 109, 102433 (2020). https://doi.org/10.1016/j.jaut.2020.102433

Saghir, S.A.M., AlGabri, N.A., Alagawany, M.M., Attia, Y.A., Alyileili, S.R., Elnesr, S.S., et al.: Chloroquine and hydroxychloroquine for the prevention and treatment of COVID-19: a fiction, hope or hype? An updated review. Ther. Clin. Risk Manag. 17, 371-387 (2021)

Scientists suggest twin antibodies for the treatment of COVID-19: here's what that means. Firstpost. https://www.firstpost.com/ health/scientists-suggest-twin-antibodies-for-the-treatment-ofcovid-19-heres-what-that-means-8367931.html. Accessed 18 May 2020

Shanghai Institute of Materia Medica website, Chinese Academy of Sciences: A joint research team of the Shanghai Institute of Materia Medica and Shanghai Tech University discover a group of old and traditional Chinese medicines that may be efficacious in treating the novel form of pneumonia. http://www.simm.ac. cn/xwzx/kydt/202001/t20200125_5494417.html. Accessed 22 February 2020 (2020)

Shanmugaraj, B., Siriwattananon, K., Wangkanont, K., Phoolcharoen, W.: Perspectives on monoclonal antibody therapy as potential therapeutic intervention for Coronavirus disease-19 (COVID-19). Asian Pac. J. Allergy Immunol. 38(1), 10-18 (2020a)

Shanmugaraj, B., Malla, A., Phoolcharoen, W.: Emergence of novel Coronavirus 2019-nCoV: need for rapid vaccine and biologics development. Pathogens 9(2), 148 (2020b). https://doi.org/10. 3390/pathogens 9020148

Sheahan, T.P., Sims, A.C., Leist, S.R., Schäfer, A., Won, J., Brown, A.J., et al.: Comparative therapeutic efficacy of remdesivir and combination lopinavir, ritonavir, and interferon beta against MERS-CoV. Nat Commun 11(1), 1-14 (2020)

Shimabukuro-Vornhagen, A., Godel, P., Subklewe, M., Stemmler, H.J., Schloßer, H.A., Schlaak, M., et al.: Cytokine release syndrome. J. Immunother. Cancer 6(1), 56 (2018). https://doi.org/10.1186/ s40425-018-0343-9

Shimizu, Y., Yamamoto, S., Homma, M., Ishida, N.: Effect of chloroquine on the growth of animal viruses. Arch. Gesamte Virusforsch 36(1), 93-104 (1972)

Silva, L.H.A., Antunes, M.A., Dos Santos, C.C., Weiss, D.J., Cruz, F.F., Rocco, P.R.M.: Strategies to improve the therapeutic effects of mesenchymal stromal cells in respiratory diseases. Stem Cell Res. Ther. 9(1), 45 (2018). https://doi.org/10.1186/ s13287-018-0802-8

Sorrento and Celularity to initiate emergency allogeneic natural killer (NK) cell therapy development for coronavirus infection. https:// 
seekingalpha.com/pr/17762358-sorrento-and-celularity-to-initi ate-emergency-allogeneic-naturalkiller-nk-cell-therapy. Accessed 01 Apr 2020.

Ströher, U., DiCaro, A., Li, Y., Strong, J.E., Aoki, F., Plummer, F., et al.: Severe acute respiratory syndrome-related coronavirus is inhibited by interferon-alpha. J. Infect. Dis. 189(7), 1164-1167 (2004)

Su, S., Wong, G., Shi, W., Liu, J., Lai, A.C.K., Zhou, J., Liu, W., Bi, Y., Gao, G.F.: Epidemiology genetic recombination, and pathogenesis of coronaviruses. Trends Microbiol. 24, 490-502 (2016)

Tian, X., Li, C., Huang, A., Xia, S., Lu, S., Shi, Z., et al.: Potent binding of 2019 novel coronavirus spike protein by a SARS coronavirus-specific human monoclonal antibody. Emerg. Microbes Infect. 9(1), 382-385 (2020)

Tortorici, M.A., Veesler, D.: Structural insights into coronavirus entry. Adv. Virus Res. 105, 93-116 (2019)

Tu, H., Tu, S., Gao, S., Shao, A., Sheng, J.: The epidemiological and clinical features of COVID-19 and lessons from this global infectious public health event. J. Infect. 81(1), 1-9 (2020)

Vaccine BCG may provide immune boost against coronavirus, herpes, and other viral infections. Medicalxpress News. https://medic alxpress.com. Accessed 23 Mar 2020.

Walls, A.C., Xiong, X., Park, Y.J., Tortorici, M.A., Snijder, J., Quispe, J., et al.: Unexpected receptor functional mimicry elucidates activation of coronavirus fusion. Cell 176, 1026-1039 (2019)

Walls, A.C., Park, Y.J., Tortorici, M.A., Wall, A., McGuire, A.T., Veesler, D.: Structure, function and antigenicity of the SARSCoV-2 spike glycoprotein. bioRxiv (2020). https://doi.org/10. $1101 / 2020.02 .19 .956581$

Wan, Y., Shang, J., Graham, R., Baric, R.S., Li, F.J.: An analysis based on decade-long structural studies of SARS 3, JVI Accepted Manuscript Posted Online 29 January 2020. J. Virol. (2020). https:// doi.org/10.1128/JVI.00127-20

Wang, C., Horby, P.W., Hayden, F.G., Gao, G.F.: A novel coronavirus outbreak of global health concern. Lancet 395, 470-473 (2020a)

Wang, M., Cao, R., Zhang, L., Yang, X., Liu, J., Xu, M., et al.: Remdesivir and chloroquine effectively inhibit the recently emerged novel coronavirus (2019-nCoV) in vitro. Cell Res. 30(3), 269271 (2020b). https://doi.org/10.1038/s41422-020-0282-0

Wang, W., Tang, J., Wei, F.: Updated understanding of the outbreak of 2019 novel coronavirus (2019-nCoV) in Wuhan, China. J. Med. Virol. 92(4), 441-447 (2020c)

Wang, Y., Wang, Y., Chen, Y., Qin, Q.: Unique epidemiological and clinical features of the emerging 2019 novel coronavirus pneumonia (COVID-19) implicate special control measures. J. Med. Virol. 92(6), 568-576 (2020d)

Wang, Z., Chen, X., Lu, Y., Chen, F., Zhang, W.: Clinical characteristics and therapeutic procedure for four cases with 2019 novel coronavirus pneumonia receiving combined Chinese and Western medicine treatment. Biosci. Trends 14, 64-68 (2020e)

Wei, F.P.: Diagnosis and treatment protocol for novel coronavirus pneumonia (Trial version 7) released by National Health Commission \& National Administration of Traditional Chinese Medicine. Chin. Med. J. 133(9), 1087-1095 (2020)

Weiss, S.R., Leibowitz, J.L.: Coronavirus pathogenesis. Adv. Virus Res. 81, 85-164 (2011). https://doi.org/10.1016/B978-0-12385885-6.00009-2

World Health Organization: Modes of transmission of virus causing COVID-19: implications for IPC precaution recommendations. https://www.who.int/news-room/commentaries/detail/modesof-transmission-of-virus-causingcovid-19-implications-for-ipcprecaution-recommendations. Accessed 30 March 2020 (2020a)

World Health Organization: Status of COVID-19 vaccines within WHO EUL/PQ evaluation process. https://www.who.int/emergencies/ diseases/novel-coronavirus-2019/covid-19-vaccines. Accessed 15 July 2021 (2021b)
World Health Organization: COVID-19-Landscape of novel coronavirus candidate vaccine development worldwide. https://www.who. int/teams/blueprint/covid-19/covid-19-vaccine-tracker-and-lands cape. Accessed 27 July 2021 (2021)

Wrapp, D., Wang, N., Corbett, K.S., Goldsmith, J.A., Hsieh, C.L., Abiona, O., et al.: Cryo-EM structure of the 2019-nCoV spike in the prefusion conformation. Science 367(6483), 1260-1263 (2020). https://doi.org/10.1126/science.abb2507

Wu, A., Peng, Y., Huang, B., Ding, X., Wang, X., Niu, P., et al.: Genome composition and divergence of the novel coronavirus (2019-nCoV) originating in China. Cell Host Microbe 27, 325328 (2020a). https://doi.org/10.1016/j.chom.2020.02.001

Wu, F., Zhao, S., Yu, B., Chen, Y.M., Wang, W., Song, Z.G., et al.: A new coronavirus associated with human respiratory disease in China. Nature 579(7798), 265-269 (2020b)

Wu, J.T., Leung, K., Leung, G.M.: Nowcasting and forecasting the potential domestic and international spread of the 2019-nCoV outbreak originating in Wuhan, China: a modelling study. Lancet 395(10225), 689-697 (2020c)

Xu, X.W., Wu, X.X., Jiang, X.G., Xu, K.J., Ying, L.J., Ma, C.L., et al.: Clinical findings in a group of patients infected with the 2019 novel coronavirus (SARS-Cov2) outside of Wuhan, China: retrospective case series. BMJ 368, m606 (2020). https://doi.org/ 10.1136/bmj.m606

Yamada, Y., Liu, D.X.J.: Virol 83, 8744-8758 (2009)

Yang, P., Wang, X.: COVID-19: a new challenge for human beings. Cell \& Mol Immuno 17, 555-557 (2020)

Yao, X., Ye, F., Zhang, M., Cui, C., Huang, B., Niu, P., et al.: In vitro antiviral activity and projection of optimized dosing design of hydroxychloroquine for the treatment of severe acute respiratory syndrome coronavirus 2 (SARS-CoV-2). Clin Infect Dis 71(15), 732-739 (2020)

Yu, F., Du, L., Ojcius, D.M., Pan, C., Jiang, S.: Measures for diagnosing and treating infections by a novel coronavirus responsible for a pneumonia outbreak originating in Wuhan, China. Microbes Infect. 22(2), 74-79 (2020). https://doi.org/10.1016/j.micinf. 2020.01.003

Zhang, L., Liu, Y.: Potential interventions for novel coronavirus in China: a systemic review. J. Med. Virol. 92(5), 479-490 (2020). https://doi.org/10.1002/jmv.25707

Zhang, Y., Xu, J.M.: Medical diagnosis and treatment strategies for malignant tumors of the digestive system during the outbreak of novel coronavirus pneumonia. Chin. J. Oncol. 42, E005-E005 (2020)

Zhang, C., Zheng, W., Huang, X., Bell, E.W., Zhou, X., Zhang, Y.: Protein structure and sequence re-analysis of 2019-nCoV genome refutes snakes as its intermediate host or the unique similarity between its spike protein insertions and HIV-1. J. Proteome Res. 19, 1351-1360 (2020a). https://doi.org/10.1021/acs.jproteome. 0c00129

Zhang, D.H., Wu, K.L., Zhang, X., Deng, S.Q., Peng, B.: In silico screening of Chinese herbal medicines with the potential to directly inhibit 2019 novel coronavirus. J. Int. Med. 18(2), 152$158(2020 \mathrm{~b})$

Zhang, H., Kang, Z., Gong, H., Xu, D., Wang, J., Li, Z., et al.: Digestive system is a potential route of COVID-19: an analysis of single-cell coexpression pattern of key proteins in viral entry process. Gut 69(6), 320953 (2020c). https://doi.org/10.1136/ gutjnl-2020-320953

Zhang, J., Zhou, L., Yang, Y., Peng, W., Wang, W., Chen, X.: Therapeutic and triage strategies for 2019 novel coronavirus disease in fever clinics. Lancet Respir. Med. 8, e11-12 (2020d). https:// doi.org/10.1016/S2213-2600(20)30071-0

Zhang, Q., Wang, Y., Qi, C., Shen, L., Li, J.: Clinical trial analysis of 2019-nCoV therapy registered in China. J. Med. Virol. 92(6), 540-545 (2020e) 
Zhang, T., Wu, Q., Zhang, Z.: Probable pangolin origin of SARSCoV-2 Assoc. Curr Biol 30(7), 1346-1351 (2020f). https://doi. org/10.1016/j.cub.2020.03.022

Zhou, P., Yang, X.L., Wang, X.G., Hu, B., Zhang, L., Zhang, W., et al.: A pneumonia outbreak associated with a new coronavirus of probable bat origin. Nature 579(7798), 270-273 (2020a). https:// doi.org/10.1038/s41586-020-2012-7

Zhou, W., Liu, Y., Tian, D., Wang, C., Wang, S., Cheng, J., et al.: Potential benefits of precise corticosteroids therapy for severe 2019-nCoV pneumonia. Signal Trans. Target. Ther. 5, 18 (2020b). https://doi.org/10.1038/s41392-020-0127-9
Zhu, N., Zhang, D., Wang, W., Li, X., Yang, B., Song, J., et al.: A novel Coronavirus from patients with pneumonia in China, 2019. N. Engl. J. Med. 382(8), 727-733 (2020). https://doi.org/10.1056/ NEJMoa2001017

Zorzitto, J., Galligan, C.L., Ueng, J.J., Fish, E.N.: Characterization of the antiviral effects of interferon- $\alpha$ against a SARS-like coronavirus infection in vitro. Cell Res. 16, 220-229 (2006). https://doi. org/10.1038/sj.cr.7310030

Zumla, A., Chan, J.F., Azhar, E.I., Hui, D.S., Yuen, K.Y.: Coronaviruses-drug discovery and therapeutic options. Nat. Rev. Drug Discov. 15(5), 327-347 (2016) 